\title{
Correspondence.
}

\section{THE RECENT APPOINTMENT TO HAYWARDS HEATH ASYLUM.}

\author{
To the Editors "Journal of Mental Science."
}

SIRs,-The above "miscarriage of justice," as it has been aptly termed, appears to me to be a subject presenting many aspects for purposes of discussion. The ratepayers, for instance, may naturally complain if, after a few years' experience of the new medical superintendent to their county asylum, they are asked to provide means to superannuate him, and asylum assistant physicians may feel inclined to protest against their claims having been passed over in favour of an " outsider." It is as an advocate of the assistant medical officers of English county and borough asylums that I beg your attention. The custom in the past has been, with very rare exceptions, to select for the post of medical superintendent a candidate with experience in the medical treatment of the insane, and with a practical knowledge of the no less important duties associated with the administration of a large institution. In the present instance, however, by the appointment of an "outsider," an insult has been inflicted on those men, who, notwithstanding their having completed an apprenticeship in attaining to a requisite knowledye of these duties, have been considered unfit or unworthy to hold the higher post of superintendent.

If such appointments are to be given to "outsiders," what will be our chances of future promotion in the specialty to which we devote tic 'jest portion of our lives? and to whom can we appeal for redress if the Medico-Psychological Association fails to use whatever influence it possesses to bring the whole subject before Parliament, so that such misuse of patronage and injustice to our interests may not occur again? It is much to be regretted that, for reasons quite apparent, the Medico-Psychological Association, at a special meeting called to discuss this appointment, did not adopt the suggestion contained in the petition signed by a large majority of all the assistants in English county and borough asylums.*

I am, your obedient servant,

T. DunCaN Greenlees.

March 20th, 1888.

\section{Appointments.}

Clark, A. F. C., M.B., C.M., appointed Assistant Medical Officer to the District Asylum, Roxburgh.

Fox, R. G., M.B., C.M.Ed., appointed Junior Assistant Medical Officer to the Sussex County Lunatic Asylum.

Griffiths, T. R., appointed Clinical Assistant, Birmingham Borough

Asylum.

JoNes, RoBerT, M.D., L.R.C.P., F.R.C.S., appointed Superintendent of the Earlswood Asylum, Redhill, Surrey.

McDowAlL, JoHn G., M.D.Ed., C.M.Ed., appointed Medical Superintendent of the New Yorkshire Asylum at Menston.

SAUNDERS, C. E., M.D., M.R.C.P., M.R.C.S., appointed Medical Superintendent of the Sussex County Lunatic Asylum.

WhITwelL, J. R., M.B., C.M.Ed., appointed Pathologist to the South Yorkshire Asylum, Wadsley, near Sheffield.

* Sixty-six circulars have been sent out; 47 replies, representing 85 assistant medical officers, have been returned. Of these, 39 asylums, representing 64 assistant medical officers, have signed the petition. Six asylums, representing 10 assistant medical officers, sympathize with the agitation, but for various reasons decline to sign it, and from 16 asylums no replies have been received. I trust that these figures speak for themselves, and are convincing proof, if proof were wanting, that the call on the Association to do justice to the assistant medical officers received extensive support. 